\title{
Faktor risiko osteoporosis pada wanita usia 40-80 tahun: status menopause dan obesitas
}

Osteoporosis risk factors in women aged 40-80 years: menopausal and obesity status

\author{
Fillah Fithra Dieny, Deny Yudi Fitranti
}

Departemen Ilmu Gizi, Fakultas Kedokteran Universitas Diponegoro

\begin{abstract}
Background: Osteoporosis is a disease of the musculoskeletal system which are common in women. Menopausal status which affects the production of oestrogen and obesity status that describes mass and distribution of body fat have the potential to affect bone density, which in turn may have an impact on the incidence of osteoporosis. Objective: To analyze the menopausal and obesity status as risk factors for osteoporosis in women aged 40-80 years. Method: Cross-sectional study was conducted on 224 women aged 40-80 years in Ngemplak Simongan, Semarang. Status of obesity was determined by percent of body fat, body mass index (BMI), waist circumference, and waist-hip ratio (WHR). Menopausal status was determined based on the occurrence of menstruation in the past one year, and the age was calculated from the difference between date of birth and date of measurement. Bone density was assessed frombone mineral density measurement. Chi-square test and logistic regression were used to determine the relationship and the most influential factors. The risk was expressed in ratio prevalence (RP). Results: The prevalence of low bone density and obesity in each age range, were $43.8 \%$ and $57.9 \%$ for ages $40-50$ years, $67.7 \%$ and $58.6 \%$ for ages $51-60$ years, $84.9 \%$ and $49.1 \%$ for ages $61-70$ year, $86.7 \%$ and $66.7 \%$ for ages $71-80$ years. There were significant relationships between age, menopausal status, BMI, WHR and bone density ( $p=0.000, p=0.032, p=0.043, p=0.017$, respectively). Osteoporosis (13.3\%) and osteopenia (58.7\%) were most widely experienced by subjects with high WHR and menopause. Percentage of osteopenia in high WHR and non-menopause subjects (60\%) was higher than normal WHR and menopause subjects (52.9\%). Age 61-80 years, high WHR, and non-obese BMI were the most influenced risk factorsfor the incidence of low bone density ( $p=0.001, p=0.038, p=0.043)$. Ratio prevalence of elderly, high WHR and non-obese BMI were 1.448, 1.326, 1.208. Conclusion: High WHR explains the role of android obesity and visceral fat as risk factors for low bone density. Premenopausal women will be more at risk of having low bone density if they have high WHR.
\end{abstract}

KEY WORDS: BMI; bone density; menopause; obesity; WHR

\begin{abstract}
ABSTRAK
Latar belakang: Osteoporosis merupakan penyakit sistem muskuloskeletal yang sering terjadi pada wanita. Status menopause yang mempengaruhi produksi hormon estrogen dan status obesitas yang menggambarkan massa dan distribusi lemak dalam tubuh berpotensi mempengaruhi kepadatan tulang, yang selanjutnya dapat berdampak pada kejadian osteoporosis. Tujuan: Menganalisis status menopause dan obesitas sebagai faktor risiko osteoporosis pada wanita usia 40-80 tahun. Metode: Penelitian cross-sectional dilakukan pada 224 wanita usia 40-80 tahun di wilayah Ngemplak Simongan, Kota Semarang. Status obesitas diketahui melalui persen lemak tubuh, indeks massa tubuh (IMT), lingkar pinggang, dan rasio lingkar pinggang panggul (RLPP). Status menopause ditentukan berdasarkan kejadian menstruasi dalam 1 tahun terakhir, dan usia dihitung dari selisih antara tanggal lahir dan tanggal pengukuran. Kepadatan tulang dinilai dari hasil pengukuran bone mineral density. Uji Chi-Square dan regresi logistik digunakan untuk mengetahui hubungan dan faktor yang paling berpengaruh. Besar risiko dinyatakan dalam ratio prevalence (RP). Hasil: Prevalensi kepadatan tulang rendah dan obesitas pada tiap-tiap kelompok usia yaitu $43,8 \%$ dan $57,9 \%$ untuk usia $40-50$ tahun; $67,7 \%$ dan $58,6 \%$ untuk usia $51-60$ tahun; $84,9 \%$ dan $49,1 \%$ untuk usia $61-70$ tahun; $86,7 \%$ dan $66,7 \%$ untuk usia $71-80$ tahun. Terdapat hubungan signifikan antara usia, status menopause, IMT, dan RLPP dengan kepadatan tulang $(\mathrm{p}=0,000 ; \mathrm{p}=0,032 ; \mathrm{p}=0,043$; $\mathrm{p}=0,017$ secara berurutan). Osteoporosis $(13,3 \%)$ dan osteopenia $(58,7 \%)$ paling banyak dialami oleh subjek dengan RLPP lebih dan menopause. Persentase osteopenia pada subjek dengan RLPP lebih dan tidak menopause (60\%) lebih tinggi daripada subjek dengan RLPP normal dan menopause (52,9\%). Usia 61-80 tahun, RLPP lebih, serta IMT tidak obesitas merupakan faktor risiko yang paling berpengaruh terhadap kejadian kepadatan tulang rendah $(\mathrm{p}=0,001 ; \mathrm{p}=0,038 ; \mathrm{p}=0,043)$. Ratio prevalence usia lanjut,
\end{abstract}


RLPP lebih, dan IMT tidak obesitas, masing-masing 1,448; 1,326; 1,208. Simpulan: Rasio lingkar pinggang panggul berlebih menjelaskan peran obesitas android dan lemak visceral sebagai faktor risiko kepadatan tulang rendah. Wanita yang belum menopause akan lebih berisiko memiliki kepadatan tulang rendah jika memiliki RLPP berlebih.

KATA KUNCI: IMT; kepadatan tulang; menopause; obesitas; RLPP

\section{PENDAHULUAN}

Osteoporosis merupakan salah satu penyakit pada sistem muskuloskeletal yang paling sering terjadi dan disebut sebagai silent disease karena terjadi penurunan kepadatan tulang yang sangat progresif, namun tidak menampakkan gejala yang signifikan hingga terjadinya patah tulang (1). Patah tulang yang disebabkan oleh penyakit osteoporosis dapat menyebabkan kesakitan dan kematian (2,3). Osteoporosis terbagi menjadi dua kategori yaitu osteoporosis primer dan sekunder. Osteoporosis primer terjadi karena faktor penuaan yang menyebabkan penurunan kepadatan tulang, sedangkan osteoporosis sekunder terjadi karena penggunaan obat - obatan jangka panjang seperti glukokortikoid dan penyakit tertentu seperti malabsorpsi (4). Osteoporosis primer paling umum terjadi dan sering disebut juga "age-related osteoporosis" atau osteoporosis pascamenopause karena biasanya osteoporosis ini terdiagnosa pada usia lanjut dan wanita pascamenopause (5).

Usia merupakan salah satu faktor risiko terjadinya osteoporosis. Semakin bertambah usia maka akan terjadi peningkatan bone loss (kehilangan tulang), terutama pada lansia (6). Usia harapan hidup penduduk Indonesia adalah 72 tahun dan diprediksikan menjadi 80 tahun pada tahun 2050 (7). Seiring dengan meningkatnya usia harapan hidup di negara berkembang seperti Indonesia maka terjadi peningkatan penyakit degeneratif dan metabolik, termasuk osteoporosis (8). Penelitian yang dilakukan oleh Tirtarahardja di Indonesia pada tahun 2006 menyebutkan bahwa sebanyak $23 \%$ wanita usia 50-80 tahun mengalami osteoporosis dan 53\% dialami oleh wanita usia 70-80 tahun (9). Berdasarkan data Dinas Kesehatan Kota Semarang tahun 2012, jumlah penderita osteoporosis di Kota Semarang sebanyak 1559 orang, dari jumlah tersebut sebanyak 1154 orang $(74 \%)$ berjenis kelamin wanita dan sebanyak 682 orang $(43,7 \%)$ berusia 45-65 tahun (10). Jumlah penderita osteoporosis terbanyak berada di wilayah kerja Puskesmas Ngemplak Simongan, yaitu sebanyak 1236 orang.
Kelompok rentan seperti wanita dan lansia memiliki risiko terjadinya osteoporosis yang lebih besar dibandingkan pria atau usia yang lebih muda. Hal ini karena terjadi peningkatan kehilangan tulang seiring dengan pertambahan usia, yang lebih nyata pada wanita dibandingkan pria. Tingkat kehilangan tulang yang terjadi sebesar $0,5-1 \%$ per tahun dari berat tulang pada wanita pascamenopause dan pria usia di atas 80 tahun. 6 Hormon estrogen pada wanita akan melindungi tulang dari kehilangan massa tulang dan setelah menopause akan terjadi peningkatan resorpsi tulang yang menyebabkan osteoporosis pascamenopause $(11,12)$. Selain itu, pada masa lansia proses perombakan tulang berlangsung lebih cepat daripada proses pembentukan tulang sehingga kepadatan tulang berkurang. Hal ini karena proses berpasangan (coupling) antara perombakan dan pembentukan tulang melambat karena menurunnya aktivitas tubuh serta menurunnya hormon estrogen (pada wanita) sehingga tulang trabekula menjadi lebih berongga $(13,14)$.

Selain faktor usia, status obesitas seseorang juga berpengaruh terhadap kepadatan tulang. Beberapa penelitian menunjukkan hubungan yang negatif antara lemak tubuh dengan kepadatan tulang. Penelitian cross sectional pada pria dan wanita China yang berusia 2564 tahun menunjukkan bahwa pada kelompok yang mempunyai persentase lemak tubuh tertinggi mempunyai risiko osteopenia dan osteoporosis yang lebih besar (15). Penelitian lain pada orang dewasa berusia 47-79 menunjukkan bahwa subyek dengan abdominal fat mass yang lebih tinggi mempunyai kepadatan tulang yang lebih rendah (16). Sementara itu, penelitian tentang komposisi tubuh menunjukkan bahwa berat badan yang sama pada orang-orang muda yang mempunyai rasio lean mass : fat mass lebih tinggi berhubungan dengan massa tulang yang lebih tinggi, sementara pada wanita pascamenopause yang mempunyai rasio lean mass : fat mass lebih rendah berhubungan positif dengan massa tulang (17). Indeks massa tubuh (IMT) rendah 
berhubungan dengan rendahnya puncak massa tulang dan berpengaruh pula pada kehilangan massa tulang. Hal tersebut merupakan konsekuensi dari penurunan produksi estrogen peripheral pada wanita dengan IMT rendah. Indeks massa tubuh rendah merupakan salah satu faktor risiko fraktur tulang belakang dan tulang panggul (18). Berdasarkan latar belakang tersebut, kami ingin menganalisis apakah menopause dan obesitas merupakan faktor risiko terjadinya osteoporosis pada wanita usia lebih dari 40 tahun.

\section{BAHAN DAN METODE}

Penelitian ini merupakan penelitian analitik observasional dengan desain cross-sectional. Populasi target pada penelitian ini adalah semua wanita berusia lebih dari 40 tahun yang berada di Kota Semarang. Populasi terjangkau dalam penelitian ini adalah wanita berusia lebih dari 40 tahun yang bertempat tinggal di wilayah kerja Puskesmas Ngemplak Simongan (Kelurahan Ngemplak Simongan dan Keluharan Bongsari, Kecamatan Semarang Barat) Kota Semarang. Berdasarkan perhitungan rumus besar sampel penelitian observasional pada satu populasi dan koreksi drop out $10 \%$, diperoleh jumlah sampel minimal sebanyak 210 subjek. Metode non-probability sampling dan consecutive sampling digunakan untuk pengambilan sampel dalam penelitian ini. Berdasarkan kriteria inklusi yang telah ditetapkan, dari 276 subjek yang dilakukan screening, diperoleh jumlah subjek sebanyak 224 wanita, dan tidak ada yang mengalami drop out. Kriteria inklusi penelitian ini adalah memiliki usia $\geq 40$ tahun, dapat berkomunikasi dengan baik, tinggal menetap di wilayah kerja Puskesmas Ngemplak Simongan, serta bersedia mengikuti penelitian dengan mengisi lembar formulir Informed Consent.

Variabel dependent pada penelitian ini adalah kepadatan tulang. Kepadatan tulang didefinisikan sebagai nilai kepadatan tulang subjek yang diperoleh dengan mengukur Bone Mineral Density (BMD) pada tumit dan dinyatakan dalam T-score (SD). Kepadatan tulang dinilai rendah jika T-score <-1,0 (osteopenia -1 > T-score $>-2,5$; osteoporosis $T$-score $\leq-2,5)$, dan normal jika T-score $\geq$ -1,0 (17). Sementara itu, variabel independent meliputi usia, status menopause, serta status obesitas. Variabel usia subjek dihitung dari selisih antara tanggal lahir dan tanggal pengukuran, yang dinyatakan dalam satuan tahun. Status menopause merupakan berhentinya masa kesuburan dan masa reproduksi wanita ditandai dengan berhentinya masa menstruasi seiring bertambahnya usia dan penurunan hormon. Status menopause dikategorikan menjadi dua, yaitu menopause dan tidak menopause. Sementara itu, variabel status obesitas dalam penelitian ini dapat dinilai dari beberapa komponen, yaitu persen lemak tubuh, IMT, lingkar pinggang, dan rasio lingkar pinggang panggul (RLPP). Persen lemak tubuh merupakan penilaian jumlah lemak dalam tubuh yang hasilnya dibedakan dalam 2 kategori, yaitu normal $(\leq 35 \%)$ dan lebih (> 35\%). Indeks Massa Tubuh (IMT) merupakan penilaian untuk menggambarkan status gizi seseorang, yang didapat dari pembagian hasil pengukuran berat badan (BB) dalam $\mathrm{kg}$ dan tinggi badan (TB) dalam $\mathrm{m}^{2}$. Terdapat 5 kategori dalam IMT, yaitu underweight (IMT $<18,5$ ), normal (IMT $=18,5-22,9$ ), berisiko obesitas (IMT =23-24,9), obesitas I (IMT $=25-29,9)$, serta obesitas II (IMT $\geq 30$ ). Lingkar pinggang menggambarkan massa lemak di perut, dimana termasuk dalam kategori lebih apabila nilai hasil ukur $\geq 80 \mathrm{~cm}$. Rasio lingkar pinggang panggul digunakan untuk menggambarkan obesitas sentral, yang dilakukan dengan cara membagi hasil pengukuran lingkar pinggang dengan hasil pengukuran lingkar panggul subjek. Kategori normal untuk rasio lingkar pinggang panggul memiliki nilai $\leq 0,85$ dan kategori lebih jika nilai $>0,85$.

Wawancara langsung dengan subjek mengenai karakteristik subjek (nama, usia, alamat, pendidikan, pekerjaan, lama menopause), kebiasaan olahraga, riwayat konsumsi obat - obatan, riwayat penyakit penyerta yang dapat mempengaruhi kepadatan tulang menggunakan kuesioner penelitian.Data kepadatan tulang didapatkan dengan cara mengukur langsung menggunakan alat densitometer ultrasound oleh tenaga ahli.Data berat badan (BB) dan tinggi badan (TB) subjek didapat melalui pengukuran langsung menggunakantimbangan injak digital (ketelitian $0.1 \mathrm{~kg}$ ) dan microtoise (ketelitian $0.1 \mathrm{~cm}$ ). Data persen lemak tubuh diukur menggunakan BIA(Bioelectrical Impedance Analyzer). Selain itu, data lingkar pinggang dan lingkar panggul subjek didapat melalui pengukuran langsung menggunakan dan pita ukur. 
Data karakteristik subjek, status gizi, dan kepadatan tulang dideskripsikan dalam distribusi frekuensi. Data yang bersifat numerik disajikan dalam bentuk rerata, standar deviasi, nilai maksimum dan nilai minimum, sedangkan data bersifat kategorik disajikan dalam bentuk persentase. Uji Chi-Square digunakan untuk menganalisis hubungan variabel data kategorik. Besar risiko variabel bebas terhadap variabel terikat pada penelitian ini dilakukan dengan cara menentukan nilai RP (Ratio Prevalence). Selanjutnya, untuk menganalisis faktor yang paling berpengaruh (usia, menopause, obesitas) terhadap terjadinya osteoporosis dilakukan analisis regresi logistik.

\section{HASIL}

\section{Karakteristik subjek penelitian}

Subjek dalam penelitian ini berjumlah 224 wanita, dengan rentang usia mulai dari 40 tahun hingga 80 tahun. Berdasarkan Tabel 1 diketahui bahwa subjek memiliki lama menopause yang bervariasi, mulai dari belum mengalami menopause hingga ada yang telah mengalami menopause selama 31 tahun. Nilai rerata dari lama menopause yang dialami subjek yaitu 7,23 $\pm 7,33$ tahun. Subjek memiliki nilai rerata kepadatan tulang yang termasuk dalam kategori rendah yaitu $-1,46 \pm 0,87$ dengan nilai minimum $-4,80$ yang menunjukkan bahwa terdapat subjek yang telah mengalami osteoporosis.

Status obesitas pada subjek penelitian ini ditentukan melalui beberapa kriteria, yaitu persen lemak tubuh, Indeks Massa Tubuh (IMT), lingkar pinggang, serta rasio lingkar pinggang dan panggul (RLPP). Subjek memiliki nilai rerata persen lemak tubuh yang berlebih, yaitu sebesar $36.52 \pm 5.37$. Persen lemak yang berlebih (overfat) dalam tubuh dapat mengindikasikan terjadinya status obesitas. Hal yang sama juga ditunjukkan oleh kriteria IMT, lingkar pinggang dan RLPP. Nilai rerata IMT, lingkar pinggang, dan RLPP yang dimiliki oleh subjek, masing-masing termasuk dalam kategori obesitas dan berlebih. Hal ini menunjukkan bahwa rata-rata subjek telah berada dalam status obesitas, baik obesitas sentral yang ditunjukkan oleh lingkar pinggang dan RLPP, maupun obesitas umum yang diketahui melalui persen lemak tubuh dan IMT.

Subjek dalam penelitian ini dikelompokkan ke dalam 4 kelompok usia, yaitu kelompok usia 40-50 tahun, 51-60 tahun, 61-70 tahun, dan 71-80 tahun. Pengelompokkan ini bertujuan untuk melihat distribusi frekuensi dari status menopause, kepadatan tulang, persen lemak tubuh, IMT, lingkar pinggang, dan RLPP pada tiap-tiap jenjang usia. Tabel 2 memperlihatkan bahwa sebanyak 184 subjek (82.1\%) telah mengalami menopause. Jumlah subjek yang mengalami menopause pada masing-masing kelompok usia bertambah seiring dengan bertambahnya jenjang usia. Sebagian besar subjek (67\%) juga memiliki status kepadatan tulang yang rendah, dengan pola yang sama seperti status menopause, yaitu persentase subjek yang memiliki status kepadatan tulang rendah akan meningkat seiring dengan bertambahnya usia. Prevalensi kepadatan tulang rendah pada kelompok usia 40-50 tahun adalah sebesar $43,8 \% ; 67,7 \%$ pada usia 51-60 tahun; $84,9 \%$ pada usia $61-70$ tahun; dan $86,7 \%$ pada kelompok usia 71-80 tahun.

Jumlah subjek yang memiliki persen lemak tubuh berlebih pada masing-masing kelompok usia, lebih

Tabel 1. Nilai rerata, minimum, dan maksimum komponen karakteristik subjek

\begin{tabular}{lrrr}
\hline \multicolumn{1}{c}{ Karakteristik subjek } & \multicolumn{1}{c}{ Rerata \pm SD } & \multicolumn{1}{c}{ Minimum } & Maksimum \\
\hline Usia (tahun) & $56,24 \pm 8,83$ & 40 & 80 \\
Lama menopause (tahun) & $7,23 \pm 7,33$ & 0 & 31 \\
Kepadatan tulang (SD) & $-1,46 \pm 0,87$ & $-4,80$ & 0,80 \\
Persen lemak tubuh (\%) & $36,52 \pm 5,37$ & 17,8 & 54,5 \\
Berat badan (kg) & $59,34 \pm 11,29$ & 33,1 & 107,8 \\
Tinggi badan (cm) & $150,21 \pm 5,64$ & 132,1 & 167,0 \\
Indeks massa tubuh/IMT (kg/m $\left.{ }^{2}\right)$ & $26,26 \pm 4,51$ & 15,05 & 41,33 \\
Lingkar pinggang (cm) & $89,74 \pm 9,97$ & 56,0 & 117,0 \\
Lingkar panggul (cm) & $100,16 \pm 9,89$ & 77,0 & 160,0 \\
Rasio lingkar pinggang dan panggul & $0,89 \pm 0,07$ & 0.49 & 1,04 \\
\hline
\end{tabular}


Tabel 2. Distribusi frekuensi status menopause, kepadatan tulang, persen lemak tubuh, IMT, lingkar pinggang, dan RLPP berdasarkan kelompok usia subjek

\begin{tabular}{|c|c|c|c|c|c|}
\hline \multirow[b]{2}{*}{ Kategori } & \multicolumn{4}{|c|}{ Kelompok usia subjek $(n=224)$} & \multirow{2}{*}{$\begin{array}{c}\text { Total } \\
\text { n (\%) }\end{array}$} \\
\hline & $\begin{array}{c}\text { 40-50 tahun } \\
\text { n (\%) }\end{array}$ & $\begin{array}{c}\text { 51-60 tahun } \\
\text { n (\%) } \\
\end{array}$ & $\begin{array}{c}\text { 61-70 tahun } \\
n(\%) \\
\end{array}$ & $\begin{array}{c}\text { 71-80 tahun } \\
\text { n (\%) }\end{array}$ & \\
\hline \multicolumn{6}{|l|}{ Status menopause } \\
\hline Tidak & $32(14,3)$ & $8(3,6)$ & $0(0,0)$ & $0(0,0)$ & $40(17,9)$ \\
\hline Ya & $25(11,2)$ & $91(40,6)$ & $53(23,7)$ & $15(6,7)$ & $184(82,1)$ \\
\hline \multicolumn{6}{|l|}{ Status kepadatan tulang } \\
\hline Normal & $32(14,3)$ & $32(14,3)$ & $8(3,6)$ & $2(0,9)$ & $74(33,0)$ \\
\hline Rendah & $25(11,2)$ & $67(29,9)$ & $45(20,1)$ & $13(5,8)$ & $150(67,0)$ \\
\hline \multicolumn{6}{|l|}{ Persen lemak tubuh } \\
\hline Normal & $25(11,2)$ & $34(15,2)$ & $22(9,8)$ & $2(0,9)$ & $83(37,1)$ \\
\hline Lebih & $32(14,3)$ & $65(29,0)$ & $31(13,8)$ & $13(5,8)$ & $141(62,9)$ \\
\hline \multicolumn{6}{|l|}{$\mathrm{IMT}^{1}$} \\
\hline Underweight & $1(0,4)$ & $2(0,9)$ & $2(0,9)$ & $0(0,0)$ & $5(2,2)$ \\
\hline Normal & $12(5,4)$ & $15(6,7)$ & $15(6,7)$ & $1(0,4)$ & $43(19,2)$ \\
\hline Berisiko obesitas & $11(4,9)$ & $24(10,7)$ & $10(4,5)$ & $4(1,8)$ & $49(21,9)$ \\
\hline Obesitas I & $15(6,7)$ & $43(19,2)$ & $20(8,9)$ & $7(3,1)$ & $85(37,9)$ \\
\hline Obesitas II & $18(8,0)$ & $15(6,7)$ & $6(2,7)$ & $3(1,3)$ & $42(18,8)$ \\
\hline \multicolumn{6}{|l|}{ Lingkar pinggang } \\
\hline Normal & $15(6,7)$ & $9(4,0)$ & $9(4,0)$ & $0(0,0)$ & $33(14,7)$ \\
\hline Lebih & $42(18,8)$ & $90(40,2)$ & $44(19,6)$ & $15(6,7)$ & $191(85,3)$ \\
\hline \multicolumn{6}{|l|}{ RLPP $^{2}$} \\
\hline Normal & $24(10,7)$ & $19(8,5)$ & $9(4,0)$ & $2(0,9)$ & $54(24,1)$ \\
\hline Lebih & $33(14.7)$ & $80(35,7)$ & $44(19,6)$ & $13(5,8)$ & $170(75,9)$ \\
\hline
\end{tabular}

${ }^{1} \mathrm{IMT}=$ Indeks Massa Tubuh; ${ }^{2} \mathrm{RLPP}=$ Rasio Lingkar Pinggang dan Panggul

banyak daripada jumlah subjek yang memiliki persen lemak tubuh normal. Sementara itu, pada kategori IMT, sebanyak $37,9 \%$ subjek berada pada status obesitas I, dengan jumlah terbesar terdapat pada kelompok usia 5160 tahun (43 subjek). Hasil penelitian juga menunjukkan bahwa persentase subjek dengan obesitas (obesitas I dan obesitas II) lebih besar (56,7\%) dibandingkan subjek yang berisiko obesitas $(21,9 \%)$ ataupun subjek yang tidak obesitas (underweight dan normal $=21,4 \%$ ). Prevalensi obesitas (obesitas I dan II) pada tiap-tiap kelompok usia, yaitu 57,9\% untuk usia 40-50 tahun; 58,6\% untuk usia 51-60 tahun; 49,1\% untuk usia 61-70 tahun; serta 66,7\% untuk usia 71-80 tahun.

Distribusi frekuensi kategori lingkar pinggang berdasarkan kelompok usia menunjukkan bahwa sebanyak 73,7\% subjek usia 40-50 tahun; 90,9\% subjek usia 51-60 tahun; 83\% subjek usia 61-70 tahun; dan 100\% subjek usia 71-80 tahun telah memiliki lingkar pinggang berlebih. Prevalensi lingkar pinggang berlebih yang tinggi pada tiap-tiap kelompok usia tersebut menunjukkan bahwa rata-rata wanita berusia 40-80 tahun telah memiliki obesitas sentral. Serupa dengan hasil tersebut, RLPP subjek pada penelitian ini juga menunjukkan adanya persentase yang lebih tinggi pada kategori RLPP lebih di tiap-tiap kelompok usia.

\section{Hubungan dan besar risiko usia, status menopause, serta status obesitas terhadap status kepadatan tulang}

Usia, status menopause, dan status obesitas dapat mempengaruhi kepadatan tulang wanita sehingga dapat pula menjadi faktor dari kejadian osteoporosis. Identifikasi faktor risiko dilakukan dengan cara menganalisis besar risiko dari tiap-tiap komponen (usia, status menopause, dan status obesitas) terhadap kepadatan tulang, yang dinyatakan dalam Rasio Prevalens (RP). Status obesitas dalam penelitian ini ditentukan berdasarkan IMT, persen lemak tubuh, lingkar pinggang, dan RLPP. Tabel 3 menunjukkan bahwa subjek dengan IMT underweight memiliki persentase tertinggi pada kepadatan tulang rendah dibandingkan status IMT yang lain. Selain itu, 
terlihat pula adanya penurunan persentase kepadatan tulang rendah seiring dengan meningkatnya status IMT, kecuali persentase pada status obesitas II yang lebih tinggi daripada status obesitas I (underweight 100\%; normal $74,4 \%$; berisiko obesitas $71,4 \%$; obesitas I $61,2 \%$; obesitas II 61,9\%). Hasil tersebut memperlihatkan bahwa subjek dengan status IMT yang rendah berpotensi memiliki risiko kepadatan tulang rendah yang lebih besar daripada subjek yang berstatus IMT lebih. Oleh karena itu, untuk mengetahui besar risiko dari IMT terhadap kepadatan tulang rendah, selanjutnya IMT dibedakan ke dalam dua kategori, yaitu tidak obesitas untuk subjek berstatus underweight, normal, dan berisiko obesitas sedangkan kategori obesitas untuk status IMT obesitas I dan II.

Berdasarkan hasil pada Tabel 4, diketahui bahwa terdapat hubungan yang bermakna antara usia, status menopause, IMT, dan rasio lingkar pinggang dan panggul

Tabel 3. Distribusi frekuensi indeks massa tubuh berdasarkan status kepadatan tulang

\begin{tabular}{|c|c|c|c|}
\hline \multirow[b]{2}{*}{$\begin{array}{c}\text { Kategori } \\
\text { IMT }\end{array}$} & \multicolumn{2}{|c|}{ Status kepadatan tulang } & \multirow{2}{*}{$\begin{array}{l}\text { Total } \\
\text { n (\%) }\end{array}$} \\
\hline & $\begin{array}{c}\text { Rendah } \\
\text { n (\%) }\end{array}$ & $\begin{array}{c}\text { Normal } \\
\text { n (\%) }\end{array}$ & \\
\hline Underweight & $5(100)$ & $0(0)$ & $5(100)$ \\
\hline Normal & $32(74,4)$ & $11(25,6)$ & $43(100)$ \\
\hline Overweight & $35(71,4)$ & $14(28,6)$ & $49(100)$ \\
\hline Obesitas I & $52(61,2)$ & $33(38,8)$ & $85(100)$ \\
\hline Obesitas II & $26(61,9)$ & $16(38,1)$ & $42(100)$ \\
\hline
\end{tabular}

dengan status kepadatan tulang $(\mathrm{p}=0,000 ; \mathrm{p}=0,032$; $\mathrm{p}=0,043$; dan $\mathrm{p}=0,017$; secara berurutan). Kategori usia 61-80 tahun memiliki persentase kepadatan tulang rendah yang lebih tinggi (85,3\%) dibandingkan usia 40-60 tahun (59,0\%). Subjek yang telah mengalami menopause dan memiliki RLPP berlebih juga mempunyai persentase yang lebih tinggi pada status kepadatan tulang rendah (70,1\% dan 71,2\%) dibandingkan subjek tanpa menopause dan memiliki RLPP normal (52,5\% dan 53,7\%).

Tabel 4 menunjukkan bahwa nilai RP tertinggi terdapat pada kategori usia. RP sebesar 1.448 memiliki arti subjek yang berusia 61-80 tahun mempunyai kemungkinan 1.448 kali untuk mengalami kepadatan tulang rendah dibandingkan dengan subjek yang berumur 40-60 tahun. Subjek yang telah mengalami menopause mempunyai kemungkinan sebesar 1.335 kali untuk memiliki kepadatan tulang rendah dibandingkan subjek yang tidak mengalami menopause. Sementara itu, kategori dengan RP tertinggi yang dapat mewakili status obesitas adalah rasio lingkar pinggang dan panggul. Nilai RP sebesar 1.326 menunjukkan bahwa subjek dengan RLPP berlebih mempunyai kemungkinan 1.326 kali untuk mengalami kepadatan tulang rendah dibanding dengan subjek yang memiliki RLPP normal. Sedangkan indeks massa tubuh memiliki RP sebesar 1.208, yang berarti subjek dengan status IMT tidak obesitas memiliki risiko kepadatan tulang rendah 1.208 kali lebih besar daripada subjek dengan status IMT obesitas.

Tabel 4. Hubungan usia, status menopause, persen lemak tubuh, IMT, lingkar pinggang, dan RLPP dengan status kepadatan tulang

\begin{tabular}{|c|c|c|c|c|c|}
\hline \multirow{2}{*}{\multicolumn{2}{|c|}{ Kategori }} & \multicolumn{2}{|c|}{ Status kepadatan tulang } & \multirow[b]{2}{*}{$\mathbf{p}$} & \multirow{2}{*}{$\begin{array}{c}\text { Rasio prevalen } \\
\text { (RP) }\end{array}$} \\
\hline & & $\begin{array}{c}\text { Rendah } \\
\text { n (\%) }\end{array}$ & $\begin{array}{c}\text { Normal } \\
\text { n (\%) }\end{array}$ & & \\
\hline Usia & $\begin{array}{l}61-80 \\
40-60\end{array}$ & $\begin{array}{l}58(85,3) \\
92(59,0)\end{array}$ & $\begin{array}{l}10(14,7) \\
64(41,0)\end{array}$ & 0,000 & 1,448 \\
\hline Status menopause & $\begin{array}{l}\text { Ya } \\
\text { Tidak }\end{array}$ & $\begin{array}{c}129(70,1) \\
21(52,5)\end{array}$ & $\begin{array}{l}55(29,9) \\
19(47.5)\end{array}$ & 0,032 & 1,335 \\
\hline Persen lemak tubuh & $\begin{array}{l}\text { Lebih } \\
\text { Normal }\end{array}$ & $\begin{array}{l}92(65,2) \\
58(69,9)\end{array}$ & $\begin{array}{l}49(34,8) \\
25(30,1)\end{array}$ & 0,477 & 0,933 \\
\hline $\mathrm{IMT}^{1}$ & $\begin{array}{l}\text { Tidak obesitas } \\
\text { Obesitas }\end{array}$ & $\begin{array}{l}72(74,2) \\
78(61,4)\end{array}$ & $\begin{array}{l}25(25,8) \\
49(38,6)\end{array}$ & 0,043 & 1,208 \\
\hline Lingkar pinggang & $\begin{array}{l}\text { Lebih } \\
\text { Normal }\end{array}$ & $\begin{array}{c}130(68,1) \\
20(60,6)\end{array}$ & $\begin{array}{l}61(31,9) \\
13(39,4)\end{array}$ & 0,400 & 1,124 \\
\hline $\mathrm{RLPP}^{2}$ & $\begin{array}{l}\text { Lebih } \\
\text { Normal }\end{array}$ & $\begin{array}{c}121(71,2) \\
29(53,7)\end{array}$ & $\begin{array}{l}49(28,8) \\
25(46,3)\end{array}$ & 0,017 & 1,326 \\
\hline
\end{tabular}

${ }^{1}$ IMT $=$ Indeks Massa Tubuh; ${ }^{2}$ RLPP $=$ Rasio Lingkar Pinggang dan Panggul 
Tabel 5. Distribusi frekuensi subjek dengan status menopause dan rasio lingkar pinggang dan panggul pada kejadian osteoporosis

\begin{tabular}{lcccccc}
\hline \multirow{2}{*}{$\begin{array}{c}\text { Kategori } \\
\text { menopause }\end{array}$} & \multicolumn{3}{c}{ RLPP lebih } & \multicolumn{3}{c}{ RLPP normal } \\
\cline { 2 - 6 } & Osteoporosis & Osteopenia & Normal & Osteoporosis & Osteopenia & Normal \\
\hline Menopause & $20(13,3)$ & $88(58,7)$ & $42(28,0)$ & $3(8,8)$ & $18(52,9)$ & $13(38,2)$ \\
Tidak menopause & $1(5,0)$ & $12(60,0)$ & $7(35,0)$ & $0(0,0)$ & $8(40,0)$ & $12(60,0)$ \\
\hline
\end{tabular}

RLPP $=$ Rasio Lingkar Pinggang dan Panggul

Tabel 6. Hasil uji regresi logistik ganda

\begin{tabular}{lcc}
\hline \multirow{2}{*}{ Variabel } & \multicolumn{2}{c}{ Kepadatan tulang rendah } \\
\cline { 2 - 3 } & B (Standardized coefficient) & $\boldsymbol{p}$ \\
\hline Usia 61-80 tahun & 1,321 & 0,001 \\
$\mathrm{RLPP}^{1}$ lebih & 0,700 & 0,038 \\
$\mathrm{IMT}^{2}$ tidak obesitas & 0,628 & 0,043 \\
\hline
\end{tabular}

${ }^{1} \mathrm{RLPP}=$ Rasio Lingkar Pinggang dan Panggul; ${ }^{2} \mathrm{IMT}=$ Indeks Massa Tubuh

Kategori rasio lingkar pinggang dan panggul dalam penelitian ini dapat dijadikan sebagai kriteria untuk merepresentasikan status obesitas karena memiliki hubungan yang paling bermakna dengan status kepadatan tulang dan menunjukkan distribusi lemak dalam tubuh. Tabel 5 menunjukkan bahwa osteoporosis dan osteopenia paling banyak dialami oleh subjek yang memiliki RLPP lebih dan telah mengalami menopause (13,3\% dan 58,7\%). Pengaruh menopause terhadap kejadian osteoporosis terlihat pada persentase osteoporosis sebanyak $8,8 \%$ yang dialami oleh subjek dengan status menopause dan memiliki RLPP normal. Penelitian ini menunjukkan adanya pengaruh RLPP berlebih yang besar terhadap kepadatan tulang rendah, khususnya osteopenia. Persentase osteopenia pada subjek dengan RLPP lebih dan tidak menopause $(60 \%)$ lebih tinggi daripada subjek dengan RLPP normal dan mengalami menopause $(52,9 \%)$.

Variabel usia, status menopause, IMT, dan RLPP dianalisis lebih lanjut untuk mengetahui variabel yang paling berpengaruh terhadap kejadian kepadatan tulang rendah. Berdasarkan hasil uji regresi logistik, diketahui bahwa variabel yang berpengaruh terhadap kepadatan tulang rendah adalah usia 61-80 tahun, rasio lingkar pinggang dan panggul berlebih, serta status IMT tidak obesitas. Variabel yang memiliki pengaruh terbesar pada kejadian kepadatan tulang rendah adalah usia 61-80 tahun ( $\mathrm{p}=0,001)$, yang kemudian diikuti dengan RLPP lebih $(\mathrm{p}=0,038)$, lalu terakhir adalah IMT tidak obesitas $(p=0,043)$ (Tabel 6). Ketiga variabel tersebut memiliki nilai B yang positif terhadap kejadian kepadatan tulang rendah. Hal ini berarti bahwa subjek dengan usia yang lebih tua, RLPP yang berlebih, dan memiliki IMT yang lebih rendah akan memiliki risiko terjadinya kepadatan tulangrendah yang lebih besar daripada subjek yang berusia muda, mempunyai RLPP normal, dan IMT yang lebih besar.

\section{BAHASAN}

Kepadatan tulang yang rendah merupakan faktor risiko utama terjadinya osteoporosis, yang kemudian dapat meningkatkan risiko terjadinya fraktur. Wanita memiliki kepadatan tulang yang lebih rendah daripada laki-laki karena puncak massa tulang wanita lebih rendah dan adanya perubahan hormon yang terjadi pada masa menopause. Hasil penelitian ini menunjukkan adanya hubungan yang signifikan antara status menopause dan kepadatan tulang rendah pada wanita usia 40-80 tahun $(\mathrm{p}=0,032)$. Menopause yang dialami oleh wanita akan mengakibatkan terjadinya penurunan jumlah hormon estrogen yang dapat menyebabkan penurunan kepadatan tulang. Hal tersebut terjadi melalui mekanisme peningkatan produksi sitokin proinflamasi, dalam hal ini yaitu IL-6 yang berperan sebagai induktor pembentukan osteoklas dan merangsang aktivitas osteoklas. Penelitian kasus kontrol yang dilakukan di Denpasar pada tahun 2008 pada wanita pascamenopause menunjukkan bahwa kadar IL-6 lebih tinggi pada kelompok yang osteoporosis dibandingkan dengan kelompok yang tidak osteoporosis (18).

Faktor usia juga memiliki hubungan yang signifikan dengan kepadatan tulang rendahpada penelitian ini $(p=0,000)$. Seperti yang telah diketahui, usia merupakan 
faktor yang berhubungan erat dengan kepadatan tulang. Setelah melewati peak bone mass pada usia 30 tahun, proses perombakan tulang akan berlangsung lebih cepat daripada proses pembentukan tulang. Hal itu disebabkan oleh dua hal, yang pertama, adanya pembentukan lemak yang berlangsung lebih cepat pada usia lanjut, sehingga terjadi peningkatan massa lemak visceral dalam rongga perut. Lemak visceral diketahui memiliki pengaruh negatif terhadap kepadatan tulang melalui berbagai mekanisme, seperti peningkatan produksi sitokin proinflamasi yang dapat meningkatkan resorpsi tulang. Selain itu, lemak visceral juga memproduksi enzim aromatase dalam jumlah sedikit sehingga terjadi penurunan produksi estrogen yang kemudian mengakibatkan penurunan aktivasi osteoblast (19). Penyebab kedua yaitu, terjadinya peningkatan ekspresi PPAR 2 (faktor transkripsi spesifik untuk lemak) pada sumsum tulang yang mengakibatkan peningkatan perubahan sel stromal menjadi lemak dalam sumsum tulang. Banyaknya jumlah lemak dalam sumsum tulang menyebabkan penurunan massa tulang dalam tubuh $(20,21)$.

Hasil penelitian ini menunjukkan prevalensi kepadatan tulang rendah pada kelompok usia 40-50 tahun sebesar $43,8 \% ; 67,7 \%$ pada usia 51-60 tahun; $84,9 \%$ pada usia $61-70$ tahun; dan $86,7 \%$ pada kelompok usia 71-80 tahun. Data tersebut sesuai dengan hasil penelitian yang dilakukan di tiga provinsi di Indonesia (Sulawesi Utara, Yogyakarta, Jawa Barat) pada tahun 2008, yang membuktikan bahwa semakin bertambahnya umur, maka risiko terjadinya osteoporosis juga akan meningkat. Subjek yang berisiko osteoporosis yaitu sebanyak 15,1\% berusia 46-55 tahun; 34,3\% berusia 56-60 tahun; dan $57,3 \%$ berusia $>65$ tahun (22).

Status obesitas sering dihubungkan dengan status kepadatan tulang rendah dan kejadian osteoporosis, namun belum terdapat hasil yang konsisten dari penelitian terhadap hubungan tersebut. Beberapa penelitian menyatakan bahwa obesitas bersifat protektif terhadap osteoporosis, tetapi hasil penelitian terbaru menunjukkan bahwa obesitas dapat menjadi faktor protektif, faktor risiko ataupun tidak memiliki pengaruh signifikan terhadap kejadian osteoporosis (23). Timbulnya inkonsistensi hubungan tersebut disebabkan oleh penggunaan kriteria dan definisi yang berbeda untuk menilai status obesitas dalam suatu penelitian. Persen lemak tubuh, indeks massa tubuh, lingkar pinggang, serta rasio lingkar pinggang dan panggul digunakan untuk menilai status obesitas dalam penelitian ini. Hanya indeks massa tubuh dan rasio lingkar pinggang dan panggul dari keempat kriteria obesitas dalam penelitian ini, yang memiliki hubungan signifikan dengan kepadatan tulang ( $\mathrm{p}=0,043$ dan $\mathrm{p}=0,017$ ).

Subjek yang tergolong dalam IMT obesitas dengan kepadatan tulang rendah berjumlah $61,4 \%$ sedangkan subjek yang berstatus IMT tidak obesitas dengan kepadatan tulang rendah berjumlah $74,2 \%$. Hasil penelitian ini menunjukkan adanya faktor protektif dari IMT lebih terhadap kepadatan tulang. Terlihat bahwa status IMT underweight memiliki persentase tertinggi yaitu 100\% dalam kepadatan tulang rendah. Persentase subjek yang memiliki kepadatan tulang rendah pada penelitian ini cenderung turun seiring dengan meningkatnya status IMT. Namun, pola penurunan persentase tersebut hanya berlangsung sampai pada status obesitas I, kemudian persentase kepadatan tulang rendah kembali naik pada subjek yang memiliki status obesitas II. Penelitian tentang nilai IMT optimal yang memiliki risiko paling rendah terhadap osteoporosis pada wanita postmenopause usia 40-88 tahun di Polandia juga menunjukkan hasil serupa, yaitu nilai IMT $26,9 \mathrm{~kg} / \mathrm{m}^{2}$ (obesitas I) merupakan nilai IMT optimal dengan risiko osteopenia dan osteoporosis terendah (24).

Data dari National Health and Nutrition Examination Survey (NHANES) pada tahun 2005 hingga 2008 menyatakan bahwa IMT memiliki hubungan positif dengan kepadatan tulang, yang berarti jika subjek memiliki nilai IMT yang rendah maka kepadatan tulang yang dimiliki juga lebih rendah daripada subjek dengan nilai IMT yang lebih tinggi. Meskipun demikian, peneliti tersebut menyarankan untuk menggunakan atau mendefinisikan IMT sebagai indikator latihan pembebanan tubuh atauweight-bearing status, yang berguna dalam stimulasi osteogenesis untuk meningkatkan massa tulang, dan bukan sebagai indikasi massa lemak ataupun distribusi lemak dalam tubuh (25). Indeks massa tubuh pada penelitian ini pun tidak dapat digunakan untuk menggambarkan massa lemak ataupun distribusi lemak dalam tubuh karena subjek dengan status IMT obesitas tidak selalu memiliki massa lemak yang berlebih, 
melainkan memiliki lean body mass atau massa bukan lemak dalam tubuh yang lebih besar. Jumlah massa bukan lemak yang lebih besar, seperti otot yang dinamis, memang diketahui dapat memberikan efek protektif terhadap kepadatan tulang, melalui mekanisme weightbearing status $(26,27)$. Selain itu, massa lemak subkutan yang tinggi pada subjek dengan status obesitas juga dapat menjelaskan mengapa subjek dengan IMT lebih terlihat mempunyai faktor protektif terhadap kepadatan tulang. Penelitian terhadap wanita postmenopause di Korea menyatakan bahwa terdapat hubungan positif antara lemak subkutan dengan skor tulang trabekular. Lemak subkutan memproduksi enzim aromatase dan adiponektin yang lebih banyak daripada lemak visceral sehingga dapat meningkatkan jumlah estrogen dalam tubuh dan mengurangi laju osteoporosis (19). Subjek dengan status IMT tidak obesitas pada penelitian ini memiliki kemungkinan sebesar 1,208 kali untuk mengalami kepadatan tulang rendah dibandingkan dengan subjek yang berstatus IMT obesitas.

Rasio lingkar pinggang dan panggul sering digunakan sebagai prediktor penyakit metabolisme dan mortalitas yang lebih efisien daripada lingkar pinggang dan IMT. Penelitian ini mendapatkan hasil bahwa RLPP berlebih memiliki hubungan yang signifikan dengan kepadatan tulang rendah $(\mathrm{p}=0,017)$. Rasio lingkar pinggang dan panggul yang berlebih mengindikasikan terjadinya android obesityyang berkaitan dengan tingginya lemak visceralpada subyek. Tingginya lemak visceralpada subjek obesitas tipe android berhubungan dengan mekanisme proinflamasi yang dapat menstimulasi resorpsi tulang dan menekan pembentukan kolagen baru $(25,28)$. Distribusi lemak tubuh yang lebih tinggi pada bagian atas tubuh (android obesity) berkaitan dengan meningkatnya level glukokortikoid dalam tubuh. Kelebihan glukokortikoid pada tubuh diketahui dapat menghambat pembentukan tulang secara langsung melalui peningkatan adipogenesis pada sumsum tulang, meningkatkan hormon paratiroid yang memediasi resorpsi tulang, mengganggu hidroksilasi vitamin D pada ginjal dan absorpsi kalsium pada usus, serta menurunkan sirkulasi hormon reproduksi $(21,29,30)$. Penelitian tentang pengaruh simpanan lemak dalam tubuh terhadap mikroarsitektur tulang pada wanita postmenopause di
Korea juga menunjukkan adanya hubungan negatif antara lemak visceral dan skor tulang trabecular (19). Oleh karena itu, tidak mengherankan jika nilai besar risiko RLPP berlebih terhadap kejadian kepadatan tulang rendah pada penelitian ini cukup besar yaitu 1,326.

Setelah dilakukan uji regresi logistik terhadap keempat variabel yang memiliki hubungan signifikan dengan kepadatan tulang rendah, yaitu usia, status menopause, IMT, dan RLPP, diketahui bahwa usia lanjut (61-80 tahun) merupakan faktor yang paling berpengaruh terhadap kepadatan tulang. Menurunnya aktivitas fisik pada usia lanjut, meningkatnya produksi lemak dalam sumsum tulang, dan menopause yang dialami oleh wanita usia lanjut membuat usia menjadi faktor risiko yang paling berpengaruh terhadap kepadatan tulang wanita usia 40 tahun ke atas. Rasio lingkar pinggang dan panggul berlebih menjadi faktor risiko kedua yang paling berpengaruh terhadap kepadatan tulang pada penelitian ini. Sementara itu, status IMT yang rendah atau tidak obesitas juga berpengaruh terhadap kejadian kepadatan tulang rendah. Melalui hasil tersebut dapat diketahui bahwa status obesitas yang dinyatakan dalam kriteria rasio lingkar pinggang dan panggul lebih mencerminkan distribusi lemak dalam tubuh dan pengaruhnya terhadap kepadatan tulang, sedangkan IMT lebih mencerminkan status weight-bearing atau tekanan mekanik yang dialami oleh subjek, yang memiliki sifat proteksi terhadap kepadatan tulang (meningkatkan massa tulang) (31).

\section{SIMPULAN DAN SARAN}

Terdapat hubungan yang bermakna antara usia, status menopause, IMT, dan rasio lingkar pinggang dan panggul dengan status kepadatan tulang ( $\mathrm{p}=0,000$; $\mathrm{p}=0,032 ; \mathrm{p}=0,043 ;$ dan $\mathrm{p}=0,017$ secara berurutan $)$. Osteoporosis $(13,3 \%)$ dan osteopenia $(58,7 \%)$ paling banyak dialami oleh subjek dengan RLPP lebih dan menopause. Persentase osteopenia pada subjek dengan RLPP lebih dan tidak menopause (60\%) lebih tinggi daripada subjek dengan RLPP normal dan menopause (52,9\%). Faktor risiko yang paling berpengaruh terhadap kejadian kepadatan tulang rendah adalah usia 61-80 tahun, RLPP lebih, serta status IMT tidak obesitas ( $p=0,001$; $\mathrm{p}=0,038 ; \mathrm{p}=0,043)$. Besar risiko usia lanjut, RLPP 
berlebih, dan IMT tidak obesitas terhadap kepadatan tulang rendah, yaitu masing-masing sebesar 1,448; 1,326; dan 1,208 . Status obesitas yang digambarkan melalui rasio lingkar pinggang dan panggul lebih menjelaskan peran obesitas android ataupun lemak visceral sebagai faktor risiko pada kejadian kepadatan tulang rendah.

Sebagai upaya pencegahan agar tidak terjadi osteopeni ataupun osteoporosis pada wanita dewasa diperlukan pengelolaan berat badan agar tetap ideal sehingga tidak mengalami obesitas. Cara yang dapat dilakukan adalah dengan pengaturan makan yang seimbang dan olahraga yang teratur. Olahraga yang dilakukan sebaiknya olahraga yang bersifat pembebanan (weight bearing), selain dapat mencegah kenaikan lemak tubuh juga dapat meningkatkan kepadatan tulang.

\section{Pernyataan konflik kepentingan}

Tidak ada konflik kepentingan dalam penelitian ini.

\section{RUJUKAN}

1. Anderson JJB. Nutrition and Bone Health in Krause's Food and Nutrition Therapy. $12^{\text {th }}$ Edition. USA: Saunders Elsevier; 2009.

2. Setiyohadi B. Osteoporosis dalam buku ajar Ilmu Penyakit Dalam Jilid II. Edisi IV. Jakarta: Pusat Penerbitan Departemen Ilmu Penyakit Dalam Fakultas Kedokteran Universitas Indonesia; 2006.

3. International Osteoporosis Foundation (IOF). What is osteoporosis?. [series online] 2014 [cited 4 Maret 2015]. Available from: URL: http://www.iofbonehealth.org/whatis-osteoporosis.html.

4. Pettifor JM, Prentice A, Ward K, Cleaton-Jones P. The skeletal system in nutrition and metabolism $2^{\text {nd }}$ edition. United States of America: Wiley Blackwel; 2011.

5. Lee RD. Disease of the musculoskeletal system in nutrition theraphy and pathophysiology. $2^{\text {nd }}$ Edition. Unitated States of America: Wadsworth Cengange Learning; 2010.

6. Martono H. Penyakit tulang dan patah tulang. Dalam: Buku ajar Boedhi Darmojo geriatri (ilmu kesehatan usia lanjut). Jakarta: Balai Penerbit FK UI; 2009.

7. Mithal A, Bansal B, Kyer CS, Ebeling P. The AsiaPacific regional audit-epidemiology, costs, and burden of osteoporosis in India 2013: a report of International Osteoporosis Foundation. Indian J Endocr Metab [serial online] 2014 [cited 2017 Sep 26];18:449-54. Available from: URL: http://www.ijem.in/text.asp
8. Setiyohadi B. Osteoporosis. Dalam: Buku ajar ilmu penyakit dalam jilid II edisi IV. Jakarta: Departemen Ilmu Penyakit Dalam, Fakultas Kedokteran Universitas Indonesia; 2007.

9. Tirtarahardja G, Setyohadi B, Weynand LS, Zhou Q. Bone mineral density reference values for indonesian men and women. In: The Asia-Pacific Regional Audit; Epidemiology, Costs and Burden of Osteoporosis in 2013. International Osteoporosis Foundation. [serial online] 2013 [cited 2017 Sep 26]. Available from: URL: https://www.iofbonehealth.org/sites/default/files/media/ PDFs/Regional\%20Audits/2013-Asia_Pacific_AuditIndonesia_0_0.pdf

10. Dinas Kesehatan Kota Semarang. Profil kesehatan Kota Semarang tahun 2012. Semarang: Dinkes Kota Semarang; 2013.

11. Harvey N, Cooper C. Pencegahan penyakit: osteoporosis dan fraktur panggul. Dalam: Gizi kesehatan masyarakat. Jakarta: Penerbit Buku Kedokteran EGC; 2009.

12. Kanis JA, Mc Closkey EV, Johansson H, Cooper C, Rizzoli R, Reginster JY. European guidance for the diagnosis and management of osteoporosis in postmenopausal women. International Osteoporosis Foundation 2013;24(1):23-57.

13. Martono H. Aspek fisiologik dan patologik akibat proses menua. Dalam: Buku ajar Boedhi Darmojo geriatri (ilmu kesehatan usia lanjut). Jakarta: Balai Penerbit FK UI; 2009.

14. Lestari P. Studi literatur: berbagai faktor yang berpengaruh terhadap kejadian patah tulang pada usia lanjut. Eksplanasi 2011;6(2).

15. Hsu YH, Venners SA, Terwedow HA, Feng Y, Niu T, Li Z, et al. Relation of body composition, fat mass, and serum lipids to osteoporotic fractures in bone mineral density in Chinese Men and Women. Am J Clin Nutr 2006;83:146-54.

16. Bhupathiraju SN, Hughes BD, Hannan MT, Lichtenstein AH, Tucker KL. Centrally located body fat is associated with lower bone mineral density in older Puerto Rican adults. Am J Clin Nutr 2011;94:1063-70.

17. WHO Study Group. Assessment of fracture risk and its application to screening for postmenopausal osteoporosis: report of a WHO study group. Geneva: World Health Organization; 1994.

18. World Health Organization. Prevention and Management of Osteoporosis. Geneva: WHO; 2003.

19. Kim JH, Choi HJ, Ku EJ, Hong AR, Kim KM, Kim SW, et al. Regional body fat depots differently affect bone microarchitecture in postmenopausal Korean women. Osteoporosis Int 2006;27:1161-1168.

20. Kawai M, de Paula FJA, Rosen CJ. New insight into osteoporosis: the bone-fat connection. J Intern Med 2012;272(4):317-329. 
21. Rosen CJ, Klibanski A. Bone, fat, and body composition: evolving concepts in the pathogenesis of osteoporosis. Am J Med 2009;122(5):409-14.

22. Prihatini S, Mahirawati VK, Jahari AB, Sudiman H. Faktor determinan risiko osteoporosis di tiga provinsi di Indonesia. Media Litbang Kesehatan 2010; Vol.XX No.2.

23. Widyaningsih V. Obesity: protective or risk factor of osteoporosis? Jurnal Ilmu Berbagi: Seri Ilmu Kesehatan dan Lingkungan 2014;2:11-23.

24. Skrzek A, Koziel S, Ignasiak Z. The optimal value of BMI for the lowest risk of osteoporosis in postmenopausal women aged 40-88 years. HOMO - Journal of Comparative Human Biology 2014;65:232-239.

25. Lloyd JT, Alley DE, Hawkes WG, Hochberg MC, Waldstein SR, Orwig DL. Body mass index is positively associated with bone mineral density in US older adults. Arch Osteoporos 2014;9:175.

26. Maimoun L, Mura T, Leprieur E, Avignon A, MarianoGoulart D, Sultan A. Impact of obesity on bone mass throughout adult life: influence of gender and severity of obesity. Bone 2016;90:23-30.

27. Ho-Pham LT, Nguyen UDT, Nguyen TV. Association between lean mass, fat mass, and bone mineral density: a meta-analysis. J Clin Endocrinol Metab 2014;99(1):3038.

28. Bredella MA. Perspective: the bone-fat connection. Skeletal Radiol 2010;39:729-731.

29. Blaauw R, Albertse EC, Hough S. Body fat distribution as a risk factor for osteoporosis. S Afr Med J 1996;86(9):1081-4.

30. Shi XM, Chutkan N, Hamrick MW, Isales CM. Mechanism of glucocorticoid-induced osteoporosis: an update. InTech 2012:41-60.

31. Neustadt J, Pieczen S. Osteoporosis: beyond bone mineral density. A special report on the state of osteoporosis research for NBI. [serial online] 2012 [cited 2017 Sep 26]. Available from: URL: http://www.nbihealth.com/ supporting/osteoporosisreport.pdf 